\title{
Tuning the surface coating of IONs toward efficient sonochemical tethering and sustained liberation of topoisomerase II poisons
}

This article was published in the following Dove Press journal: International Journal of Nanomedicine

\author{
Hana Michalkova (D) \\ Vladislav Strmiska' \\ Jiri Kudr ${ }^{1,2}$ \\ Zuzana Skubalova (D) \\ Barbora Tesarova (D) \\ Pavel Svec (iD) \\ Lukas Richtera (ID) 1,2 \\ Ondrej Zitka (D) 1,2 \\ Vojtech Adam (D) 1,2 \\ Zbynek Heger (iD) ${ }^{1,2}$ \\ 'Department of Chemistry and \\ Biochemistry, Mendel University in Brno, \\ Brno CZ-613 00, Czech Republic; ${ }^{2}$ Smart \\ Nanodevices Research Group, Central \\ European Institute of Technology, Brno \\ University of Technology, Brno CZ-62I \\ 00, Czech Republic
}

Correspondence: Zbynek Heger

Department of Chemistry and

Biochemistry, Mendel University in Brno,

Zemedelska I, Brno CZ-6I3 00, Czech

Republic

Tel +420545133350

Fax +4205452I 2044

Email heger@mendelu.cz
Background: Iron oxide nanoparticles (IONs) have been increasingly utilized in a wide spectrum of biomedical applications. Surface coatings of IONs can bestow a number of exceptional properties, including enhanced stability of IONs, increased loading of drugs or their controlled release.

Methods: Using two-step sonochemical protocol, IONs were surface-coated with polyoxyethylene stearate, polyvinylpyrrolidone or chitosan for a loading of two distinct topo II poisons (doxorubicin and ellipticine). The cytotoxic behavior was tested in vitro against breast cancer (MDA-MB-231) and healthy epithelial cells (HEK-293 and HBL-100). In addition, biocompatibility studies (hemotoxicity, protein corona formation, binding of third complement component) were performed.

Results: Notably, despite surface-coated IONs exhibited only negligible cytotoxicity, upon tethering with topo II poisons, synergistic or additional enhancement of cytotoxicity was found in MDA-MB-231 cells. Pronounced anti-migratory activity, DNA fragmentation, decrease in expression of procaspase-3 and enhancement of p53 expression were further identified upon exposure to surface-coated IONs with tethered doxorubicin and ellipticine. Moreover, surface-coated IONs nanoformulations of topo II poisons exhibited exceptional stability in human plasma with no protein corona and complement 3 binding, and only a mild induction of hemolysis in human red blood cells.

Conclusion: The results imply a high potential of an efficient ultrasound-mediated surface functionalization of IONs as delivery vehicles to improve therapeutic efficiency of topo II poisons.

Keywords: doxorubicin, ellipticine, iron oxide, nanoparticles, release kinetics

\section{Introduction}

Over the past decades, nanomaterials have emerged as powerful tools in numerous biomedical applications. In recent years, an increasing number of nanomedicines has been already approved by the US Food and Drug Administration for human use and others are undergoing clinical trials. ${ }^{1}$ Iron oxide nanoparticles (IONs) are believed to be one of the promising candidates for applications including drug delivery, imaging and many others. ${ }^{2-4}$ This is due to a high biocompatibility, ability to obey external magnetic field (EMF), enabling a facile purification and controllable guiding of loaded drugs to the diseased location and low synthesis costs. ${ }^{5-7}$

As drug delivery systems, IONs usually comprise three major components: i) a magnetic core composed of iron oxide; ii) a surface layer exhibiting appropriate 
stabilization and affinity to the desired payload; and iii) payload, which is usually a bioactive molecule. ${ }^{8}$ In a large number of reports, the loading of drugs is achieved through covalent binding, limiting the generality of strategy, particularly for small molecule-based drugs that are hard to conjugate or are losing their cytotoxicity when conjugated. ${ }^{9,10}$ Therefore, efforts have been made to tailor surface layers (or coatings) that can adsorb therapeutics, enable for a controlled release kinetics profiles and also reduce the non-specific or unpleasant interactions with host. $^{11,12}$ The coating agents also protect IONs from chemical reactions and enhance their stability by preventing hydrophobic-hydrophobic interactions leading to aggregation of IONs. ${ }^{13}$ In this way, a number of reports have investigated exploitation of biocompatible, non-antigenic polymers or surfactants, including polyethylene glycol, poloxamers, starch or polyethylene imine ${ }^{14-17}$ to stabilize and functionalize surface of IONs. However, due to diverse physicochemical nature of both, surface coatings and drugs, the IONs surface coating-drug pairs need to be optimized in detail.

Topoisomerase II (topo II) poisons stimulate DNA double-strand breakage through interference with the cleavage/ligation reaction of DNA topo II. ${ }^{18}$ Such inhibition results in the genome instability and consequent cell death. ${ }^{19}$ Group of topo II poisons comprises several clinically important and highly active anti-cancer agents including doxorubicin (Dox), etoposide or mitoxantrone. Noteworthy, there are important negative consequences of using these agents, such as development of secondary malignancies, induction of cardiotoxicity and many others. $^{20,21}$ These are triggered by a low tumor tissue selectivity and accumulation in rapidly proliferating non-malignant cells. Hence, an important goal of present and future work is to maximize therapeutic efficiency of topo II poisons while minimizing their adverse effects. Indeed, among the most potent solution belongs nanomedicines-mediated delivery and sustained release of topo II poisons in targeted diseased tissue.

Therefore, the present study describes a facile production of surface-coated IONs capable to bind and release topo II poisons in slightly acidic (endosomal or hypoxic) microenvironment. Surface coating was optimized for two selected topo II poisons: (i) Dox hydrochloride, which is a hydrophilic compound and a prototype of anthracycline antibiotics ${ }^{22}$ and (ii) ellipticine (Elli), which is a highly toxic, poorly watersoluble alkaloid with a significant anti-cancer activity, but also a pronounced non-target toxicity. ${ }^{23}$ Due to a diverse nature of these two compounds, three types of IONs-surface coatings [polyoxyethylene stearate (POES), polyvinylpyrrolidone (PVP) and chitosan (Chit)] were evaluated in terms of testing the ultrasound-mediated tethering to increase loading efficiency (LE) of topo II poisons, their release kinetics, cytotoxicity and biocompatibility in vitro.

\section{Materials and methods}

\section{Chemicals}

Listed chemicals were purchased from Sigma-Aldrich (St. Louis, MO, USA) in ACS purity, unless noted otherwise.

\section{Synthesis of bare ions}

IONs were prepared through the oxidation of a $\mathrm{Fe}(\mathrm{OH})_{2}$ gel in the presence of $\mathrm{KNO}_{3}$ at $90^{\circ} \mathrm{C} .{ }^{24}$ More precisely, $12.5 \mathrm{~mL}$ of $1 \mathrm{M} \mathrm{KOH}$ solution and $25.0 \mathrm{~mL}$ of $2 \mathrm{M} \mathrm{KNO}_{3}$ were added to $81.3 \mathrm{~mL}$ of degassed Milli-Q water in screwable flask. Meanwhile, $1 \mathrm{M}$ solution of $\mathrm{Fe}_{2} \mathrm{SO}_{4} \cdot 7 \mathrm{H}_{2} \mathrm{O}$ in degassed water was prepared. Subsequently, $6.75 \mathrm{~mL}$ of $\mathrm{FeSO}_{4} \cdot 7 \mathrm{H}_{2} \mathrm{O}$ solution was mixed with the $\mathrm{KOH}$ and $\mathrm{KNO}_{3}$ solution described above. The mixture, which turned green at that point, was purged with $\mathrm{N}_{2}$ for 1 min. Flask was tightly closed with a screw cap and placed in a water bath that had been preheated to $90^{\circ} \mathrm{C}$. The flask was left in the bath for $2 \mathrm{hrs}$. After that time, the flask was taken out of the bath and cooled down at ambient temperature. The resulting black precipitate was washed several times with water. NdFe-B permanent magnet was used to speed up sedimentation of the precipitate and to facilitate the washing process.

\section{Surface coating of bare IONs}

For surface coating, $1.0 \mathrm{~mL}$ of IONs $(5 \mathrm{mg} / \mathrm{mL})$ was mixed with $1.0 \mathrm{~mL}$ of Milli-Q water containing POES, PVP or Chit in concentrations $2.5-10 \mathrm{mg} / \mathrm{mL}$. The solution was dispersed with ultrasonication for 20 mins with the power and the frequency of $80 / 320 \mathrm{~W}$ and $35 \mathrm{kHz}$, respectively (Bandelin Sonorex Super RK 31 H, Bandelin Electronic GmbH, Berlin, Germany). To remove unbound molecules, the solution was washed five-times with Milli-Q water using Nd-Fe-B permanent magnet. To quantify the amount of the organic surface coatings, solid samples were dried, weighted to $1.0-3.0 \mathrm{mg}$ and placed in tin cups. In a typical run, two bypasses (empty-folded tin cups) and sample (done in triplicate) were placed in the 
Flash 2000 Element Analyzer (Thermo Fisher Scientific, Waltham, MA, USA) and combusted at $950^{\circ} \mathrm{C}$ for $720 \mathrm{~s}$ using 2,5-bis(5-tert-butyl-benzoxazol-2-yl)thiopene as the standard and $\mathrm{K}$ factor as the calibration method. Percentage of the organic matter was recalculated as the ratio between the total sample weight and the sum of average amounts of elements (CHNS/O) determined by the analyzer.

\section{Tethering of topo II poisons}

Tethering of topo II poisons (Elli and Dox in form of Dox hydrochloride) onto the surface of surface-coated IONs was performed by mixing $1 \mathrm{~mL}$ of surface-coated IONs ( $1 \mathrm{mg} / \mathrm{mL})$ with $1 \mathrm{~mL}$ of Dox or Elli $(2 \mathrm{mg} / \mathrm{mL})$, followed by ultrasonication with power and frequency of $80 / 320 \mathrm{~W}$ and $35 \mathrm{kHz}$, respectively (Bandelin Sonorex Super RK 31 $\mathrm{H}$, Bandelin Electronic $\mathrm{GmbH}$ ) or incubation in ThermoMixer ${ }^{\circledR} \mathrm{C}$ (Eppendorf, Hamburg, Germany) for 20 mins. For both protocols, dependence of temperature on tethering was evaluated at $10^{\circ} \mathrm{C}, 20^{\circ} \mathrm{C}$ and $40^{\circ} \mathrm{C}$. Finally, IONs were washed five times with PBS to get rid of the loosely bound Dox or Elli. Finally, drug-loaded IONs were dispersed into $2 \mathrm{~mL}$ of Milli-Q water. After washing, tethering was validated and the LE was quantified by fluorescence spectroscopy through intrinsic fluorescence of Dox $\left(\lambda_{\text {exc }} 480 \mathrm{~nm}, \lambda_{\text {em }} 560 \mathrm{~nm}\right)$ or Elli $\left(\lambda_{\text {exc }} 305 \mathrm{~nm}\right.$, $\lambda_{\text {em }} 470 \mathrm{~nm}$ ) using plate reader Infinite 200 PRO (Tecan, Maennedorf, Switzerland). The LE was calculated as follows $^{25}$ :

$$
\begin{aligned}
\operatorname{LE}(\%)= & {[(\text { initial Dox } / \text { Elli })-(\text { supernatant free Dox } / \text { Elli })] / } \\
& (\text { initial Dox } / \text { Elli }) \times 100
\end{aligned}
$$

\section{Physico-chemical characterization methodologies}

The morphology of IONs was investigated using scanning electron microscope (SEM) MIRA 2 (Tescan, Brno, Czech Republic). Colloidal stability of surface-coated IONs was studied upon dispersion in Ringer's solution (6.5 g sodium chloride, $0.42 \mathrm{~g}$ potassium chloride, $0.25 \mathrm{~g}$ calcium chloride and $0.2 \mathrm{~g}$ of sodium bicarbonate dissolved in $1 \mathrm{~L}$ of water, $\mathrm{pH}$ 7.4), which is an isotonic solution mimicking plasma environment. Hydrodynamic diameter $\left(\mathrm{d}_{\mathrm{hy}}\right)$, $\zeta$-potential and polydispersity index (PDI) were evaluated using Doppler microelectrophoresis and quasielastic dynamic light scattering on Zetasizer Nano ZS90 (Malvern Instruments, Malvern, UK). The refractive index of dispersive environment was
1.333 for all tested samples. For each $\zeta$-potential measurement, number of runs varied between 20 and 40, and calculations considered the diminution of particle concentration based on the Smoluchowski model, with an $\mathrm{F}(\mathrm{ka})$ of 1.5. Analyses were performed in Ringer's solution (100-fold diluted with Milli-Q water) or fully supplemented culture medium (30 mins incubation in RPMI-1640 with 10\% FBS). For mass-normalization in experiments comparing the effect of surfacecoated IONs with and without tethered Dox and Elli, the total Fe content in IONs was quantified using atomic absorption spectrometer (AAS) Agilent 280ZAA with Zeeman background correction at primary wavelength $248.3 \mathrm{~nm}$ (Agilent Technologies, Santa Clara, CA, USA).

\section{In vitro release kinetics of topo II poisons from surface-coated ions}

$1 \mathrm{~mL}$ of surface-coated or bare IONs with tethered Dox and Elli (both $200 \mu \mathrm{g} / \mathrm{mL}$ ) was dispersed in solutions mimicking physiological conditions. These were: i) Ringer's solution mimicking plasma (composition described above), ii) buffer mimicking neutral intracellular fluid $(0.212 \mathrm{~g}$ magnesium chloride hexahydrate, $6.415 \mathrm{~g}$ sodium chloride, $0.318 \mathrm{~g}$ calcium chloride tetrahydrate, $0.179 \mathrm{~g}$ sodium sulfate decahydrate, $0.148 \mathrm{~g}$ disodium phosphate, $2.703 \mathrm{~g}$ sodium bicarbonate, $0.18 \mathrm{~g}$ sodium tartrate dihydrate, $0.144 \mathrm{~g}$ trisodium citrate dihydrate, $0.175 \mathrm{~g}$ sodium lactate, $0.118 \mathrm{~g}$ glycine and $0.172 \mathrm{~g}$ sodium pyruvate in $1 \mathrm{~L}$ of water, $\mathrm{pH}$ 6.9), and iii) buffer mimicking acidic environment of endosomes $0.142 \mathrm{~g}$ disodium phosphate, $6.650 \mathrm{~g}$ sodium chloride, $0.071 \mathrm{~g}$ sodium sulfate, $0.029 \mathrm{~g}$ calcium chloride dihydrate, $0.45 \mathrm{~g}$ glycine and $4.1 \mathrm{~g}$ potassium hydrogen phthalate in $1 \mathrm{~L}$ of water, $\mathrm{pH} 5.0$ ). The temperature was maintained at $37^{\circ} \mathrm{C}$. At fixed time intervals, IONs were immobilized by a permanent magnet and 50 $\mu \mathrm{L}$ of medium was withdrawn and subsequently replaced with fresh medium to maintain the sink conditions. ${ }^{25}$ The amount of released Dox and Elli was determined using plate reader Infinite 200 PRO (Tecan) at $\lambda_{\text {exc }} 480 \mathrm{~nm}, \lambda_{\text {em }} 560 \mathrm{~nm}$ for Dox and $\lambda_{\text {exc }} 305 \mathrm{~nm}, \lambda_{\text {em }} 470 \mathrm{~nm}$ for Elli. The cumulative release was calculated as follows:

Cumulative release $(\%)=($ Dox $/$ Elli in the medium $) /$ $($ Initial Dox $/$ Elli $) \times 100$

\section{Cell lines and culture conditions}

Cell lines used in this study were: i) the HBL-100 epithelial human cell line established from milk of apparently healthy woman, ii) the HEK-293 established from human 
embryonic kidney, and iii) the MDA-MB-231 established from a pleural effusion of a 51-year-old woman with triple-negative metastatic breast cancer. Cell lines were purchased from American Type Culture Collection (Manassas, VA, USA). HBL-100 and HEK-293 cell lines were cultured in DMEM and MDA-MB-231 cells were cultured in Roswell Park Memorial Institute (RPMI-1640). Media were supplemented with $10 \%$ FBS and penicillin $(100 \mathrm{U} / \mathrm{mL})$ and streptomycin $(0.1 \mathrm{mg} / \mathrm{mL})$. The cells were maintained at $37^{\circ} \mathrm{C}$ in a humidified incubator Galaxy ${ }^{\circledR} 170$ R (Eppendorf, Hamburg, Germany).

\section{Cytotoxicity screenings and analysis of IONs-topo II poisons synergism}

Treatments were initiated after the cells reached $\sim 60-80 \%$ confluence. Cells were harvested by trypsinization, washed four times with phosphate-buffered saline (PBS, $\mathrm{pH} 7.4$ ) and counted using Countess II FL Automated Cell Counter (Thermo Fisher Scientific). Viability was assayed using XTT (2,3-bis-(2-methoxy-4-nitro-5-sulfophenyl)-2H-tetrazolium-5-carboxanilide) assay. Briefly, the suspension of 5,000 cells in $100 \mu \mathrm{L}$ DMEM or RPMI-1640 was added to each well of microtiter plates, followed by incubation for 24 rs at $37^{\circ} \mathrm{C}$ with $5 \% \mathrm{CO}_{2}$ to ensure cell growth. Then, 50 $\mu \mathrm{L}$ of media containing annotated treatment agent was added to the cells. Upon $24 \mathrm{hrs}$ incubation, $25 \mu \mathrm{L}$ of XTT/ phenazine methosulfate mixture was added directly to each well followed by incubation $\left(2 \mathrm{hrs}\right.$ at $\left.37^{\circ} \mathrm{C}\right)$. Absorbance of the samples was determined at $450 \mathrm{~nm}$ (Infinite $200 \mathrm{PRO}$, Tecan). Level of IONs-topo II poisons synergism was analyzed using the Chou-Talalay analysis ${ }^{26}$ by plotting isobolograms and determining combination indices (CI) using CompuSyn software (www.combosyn.com).

\section{Quantitation of total intracellular iron}

The total content of intracellular iron from IONs was determined using a 280ZAA (AAS) (Agilent) with electro-thermal atomization. Iron was quantified at primary wavelength $248.3 \mathrm{~nm}$ (spectral bandwidth $0.5 \mathrm{~nm}$ ). Zeeman background correction was used with a field strength of $0.8 \mathrm{~T}$. Prior to analyses, iron was extracted from $10 \mu \mathrm{g}$ of cell pellet (cells were treated with IONs normalized to $5 \mu \mathrm{g} / \mathrm{mL}$ of tethered topo II poisons for 6 hrs) using $200 \mu \mathrm{L}$ of Suprapur ${ }^{\circledR} \mathrm{HNO}_{3}$ and $300 \mu \mathrm{L}$ of MilliQ water $\left(140^{\circ} \mathrm{C}, 30\right.$ mins using Multiwave 3000, Anton Paar, Graz, Austria). Before extraction, cells were washed with $10 \mu \mathrm{M}$ ethylenediaminetetraacetic acid (EDTA).

\section{Investigation of internalization of topo II poisons-tethered IONs}

Cells $\left(\sim 3 \times 10^{3}\right)$ were dispersed onto each object chamber slides (Thermo Fisher Scientific). Following incubation for $24 \mathrm{hrs}$ at $37^{\circ} \mathrm{C}$, the chambers were washed with PBS and the cells were incubated with Dox@IONs-POES and Elli@IONs-PVP (5 $\mu \mathrm{g} / \mathrm{mL}$ of each topo II poison) up to 6 hrs. After washing with PBS (3 times), the cells fixed with 4\% paraformaldehyde solution for $20 \mathrm{mins}$ and washed with PBS containing $0.1 \%$ Triton X-100 for 3 times. The cell nuclei were counterstained with Hoechst 33258. The fluorescence images were obtained using confocal laser scanning microscope (CLSM) LSM 880 (Carl Zeiss, Jena, Germany).

\section{Wound-healing assay (Scratch test)}

The cells were seeded into 6-well plate and incubated to reach the $\sim 100 \%$ confluence. Then, a pin was used to create an artificial wound in the confluent monolayer. The wells were washed with PBS to remove cells and to form a cell-free zone. Then, cells were re-suspended in a fresh medium containing either Dox@IONs-POES or Elli@IONs-PVP (5 $\mu \mathrm{g} / \mathrm{mL}$ of each topo II poison). After $24 \mathrm{hrs}$ incubation, the pictures of cells were taken and compared with pictures obtained at start-point $(0 \mathrm{hr})$, using TScratch software (CSElab, Zurich, Switzerland).

\section{Single-cell gel electrophoresis (SCGE)}

The cells were seeded at a density of $\sim 10^{6}$ cells/well in sixwell dishes and treated with Dox@IONs-POES or Elli@IONs-PVP ( $5 \mu \mathrm{g} / \mathrm{mL}$ of each topo II poison) for 6

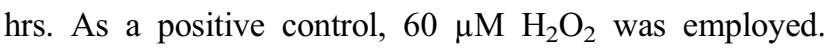
After harvesting by trypsinization and centrifugation, about $15 \mu \mathrm{L}$ of the cell suspension was mixed with $75 \mu \mathrm{L}$ of $0.5 \%$ low melting point agarose (CLP, San Diego, CA, USA) and layered on one end of a frosted plain glass slide. Then, it was covered with a layer of the low melting agarose $(100 \mu \mathrm{L})$. After solidification of the gel, the slides were immersed in a lysing solution $(2.5 \mathrm{M} \mathrm{NaCl}, 100 \mathrm{mM} \mathrm{Na} 2$ EDTA, $10 \mathrm{mM}$ Tris, $\mathrm{pH} 10$ ) containing $1 \%$ Triton $\mathrm{X}-100$ and $10 \%$ dimethyl sulfoxide overnight incubation at $4{ }^{\circ} \mathrm{C}$. A cold alkaline electrophoresis buffer was poured into the chamber and incubated for 20 mins at $4^{\circ} \mathrm{C}$. The electrophoresis was carried at $4^{\circ} \mathrm{C}$ for $30 \mathrm{mins}$, at $(1.25 \mathrm{~V} / \mathrm{cm})$ and $300 \mathrm{~mA}$. The slides were 
neutralized (0.4 M Tris, $\mathrm{pH} 7.5)$ and then stained with ethidium bromide $(2 \mu \mathrm{g} / \mathrm{mL})$. The cells were analyzed under EVOS FL Auto Cell Imaging System (Thermo Fisher Scientific) and classified according to the shape of the fluorescence of the comet tail [0 (no visible tail) to 4 (significant DNA in tail)].

\section{Hemocompatibility}

Hemocompatibility of Dox@IONs-POES or Elli@IONs-PVP was assayed using red blood cells (RBCs, Zen-Bio, Durham, NC, USA). After thawing, RBCs were washed with $150 \mathrm{mM}$ $\mathrm{NaCl}$ solution three-to-five times. Then, annotated concentrations of Dox@IONs-POES or Elli@IONs-PVP diluted in PBS were mixed with RBCs and incubated for $1 \mathrm{hr}$ at $37^{\circ} \mathrm{C}$. The degree of hemolysis was determined by quantifying the absorbance of the supernatant at $540 \mathrm{~nm}$, after centrifugation and calculated according to following equation:

$$
\left.\% \text { hemolysis }=\left[\left(A_{t}-A_{c}\right) / A_{100 \%}-A_{c}\right)\right] \times 100
$$

where $A_{t}$ is the absorbance of the supernatant from samples incubated with IONs; $A_{c}$ is the absorbance of the supernatant from negative control (PBS, $\mathrm{pH}$ 7.4); $\mathrm{A}_{100 \%}$ is the absorbance of the supernatant of positive control $(0.1 \%$ Triton X-100), which causes complete lysis of RBCs.

\section{Analysis of the formation of protein coronas}

IONs-containing solutions (normalized to iron content by AAS) were incubated in human serum (from male $A B$ clotted whole blood) at 1:1 volume ratio ( $\mathrm{v} / \mathrm{v})$ in order to mimic the protein concentration in vivo $(50 \%$ plasma in blood). The incubation was done for $1 \mathrm{hr}$ at $37^{\circ} \mathrm{C}$ under continuous agitation $(450 \mathrm{rpm})$. The protein coronas were recovered after 10 mins centrifugation at $15,000 \times \mathrm{g}$, and washed five times with cold PBS to remove the unbound proteins. Finally, the proteins were eluted by adding SDS, separated by $12 \%$ one-dimensional SDS-polyacrylamide gel electrophoresis (SDS-PAGE) and stained by Coomassie brilliant blue. Gels were visualized using Azure c600 (Azure Biosystems, Dublin, CA, USA). Plasma proteins were also quantified by densitometric analysis with the AzureSpot software (Azure Biosystems).

\section{Western blotting}

Upon treatment with Dox@IONs-POES or Elli@IONs-PVP ( $5 \mu \mathrm{g} / \mathrm{mL}$ of each topo II poison, $6 \mathrm{hrs}$ ), total cellular proteins from MDA-MB-231 cells were extracted with $100 \mu \mathrm{L}$ of
RIPA buffer containing protease inhibitor cocktail. After electrophoresis, the proteins were electrotransferred onto the Immuno-Blot ${ }^{\circledR}$ PVDF membrane (Bio-Rad, Hercules, CA, USA) and blocked with $10 \%(\mathrm{w} / \mathrm{v})$ skim milk powder for $1 \mathrm{hr}$ at $37^{\circ} \mathrm{C}$. Membranes were incubated with primary mouse anti-GAPDH (1:700), mouse anti- $\beta$-actin (1:700), mouse anti-Bcl-2 (1:200), mouse anti-p53 (1:250), mouse anti-MT1-1/2 (1:200) and mouse anti-MT-3 (1:200). After washing, membranes were incubated with relevant horseradish peroxidase-labeled secondary antibody (p0260, 1:5,000, Dako, Glostrup, Denmark) for $1 \mathrm{hr}$ at $20^{\circ} \mathrm{C}$. Signals were developed using Clarity Western ECL Blotting Substrate (Bio-Rad) and blots were visualized using Azure c600 imager (Azure Biosystems).

\section{Evaluation of binding of third complement component (C3)}

Upon incubation in human serum from male $A B$ clotted whole blood at $1: 1$ ratio $(\mathrm{v} / \mathrm{v})$ for $1 \mathrm{hr}$ at $37^{\circ} \mathrm{C}$, surfacecoated IONs bound proteins were electrophoresed and electrotransferred onto the Immobilion ${ }^{\circledR}$-FL membrane (EMD Millipore, Burlington, MA, USA). Blocking and immunoblotting of $\mathrm{C} 3$ was performed as described above using the $\mathrm{C} 3$ monoclonal antibody, LF-MA0132, Thermo Fisher Scientific, dilution 1:1,000.

\section{Descriptive statistics}

For the statistical evaluation of the results, the mean was taken as the measurement of the main tendency, while positive and negative error was taken as the dispersion measurement. Differences between groups were analyzed using paired $t$-test and ANOVA. For analyses, Software Statistica 12 (StatSoft, Tulsa, OK, USA) was employed.

\section{Results}

\section{Preparation and characterization of bare and surface-coated ions}

Bare IONs were synthesized through the oxidation of $\mathrm{Fe}$ $(\mathrm{OH})_{2}$ gel in the presence of $\mathrm{KNO}_{3}$ at $90^{\circ} \mathrm{C}$ according to Sugimoto and Matijevic. ${ }^{24}$ To stabilize bare IONs and to functionalize their surface, three distinct types of organic layers (PVP, POES or Chit) were deposited through ultrasound-mediated coating process. ${ }^{27}$ This was followed by an extensive washing and optimization of a tethering of two selected topo II poisons, Dox and Elli (synthesis procedure is schematized in Figure 1A). The morphology 
and particle size of bare and surface-coated IONs were observed under SEM. As shown in Figure 1B, bare IONs were spherical-to-polyhedral with the core having diameter $\sim 420 \mathrm{~nm}$. Noteworthy, ultrasound-mediated deposition of organic coatings caused apparent slight collisions in IONs surface, which is in line with the study by Sodipo et $\mathrm{al}^{27}$. Resulting surface organic matter formed $0.1 \%$ (POES), $0.2 \%$ (PVP) or $0.9 \%$ (Chit) of total IONs weight (Figure 1C). This confirms a successful coating procedure and indicates a thin surface coating of IONs. Moreover, Figure 1D illustrates that organic surface coatings enhanced the colloidal stability of IONs dispersed in Ringer's solution and contrary to bare IONs, sedimentation started after approx. $12 \mathrm{hrs}$ incubation. To further predict the colloidal stability of IONs in vivo, their $d_{\text {hy }}$ in the Ringer's solution (buffer mimicking plasma environment) was monitored over time. As shown in Figure 1E, the highest increase in particle $d_{\text {hy }}$ was found for bare IONs. For surface-coated IONs, agglomeration occurred slowly and in much lesser extent. This phenomenon was further confirmed by quantifying PDI (Figure 1F), indicating the lowest stability for bare IONs. Overall, the results confirmed a successful surface coating of IONs with beneficial properties toward their stability in physiological environment.

\section{Surface tethering of topo II poisons}

After surface coating of IONs, tethering of Dox and Elli was optimized in terms of tethering time, surface-coating agents' concentrations, incubation temperature and involvement of
A
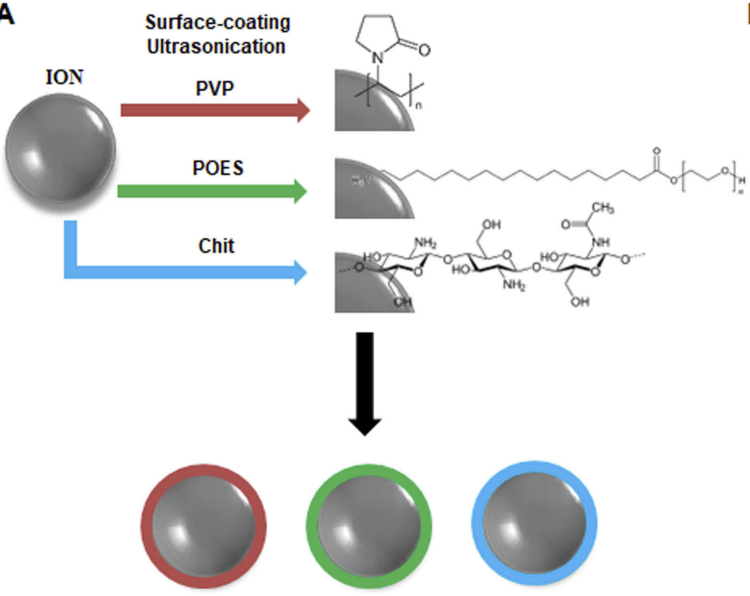

IONs-PVP

Drug complexation - incubation vs. ultrasonication
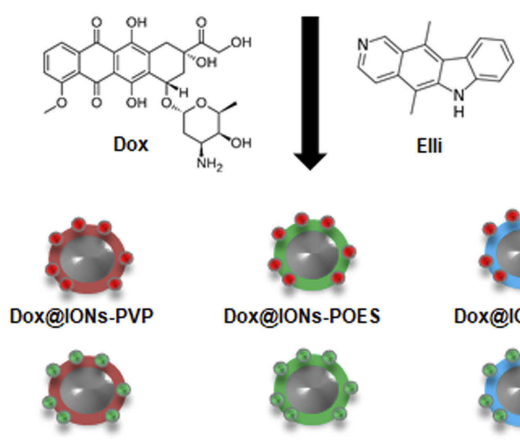

Elli@IONS-POES

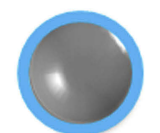

IONs-Chit
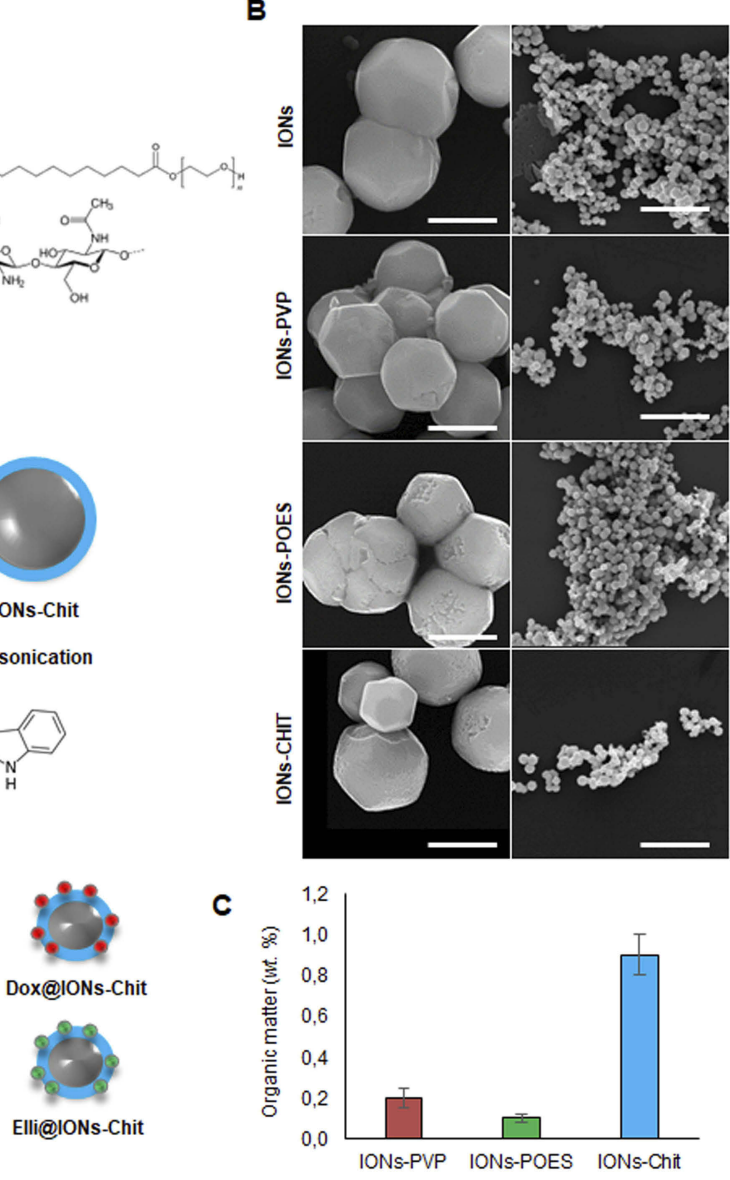

D
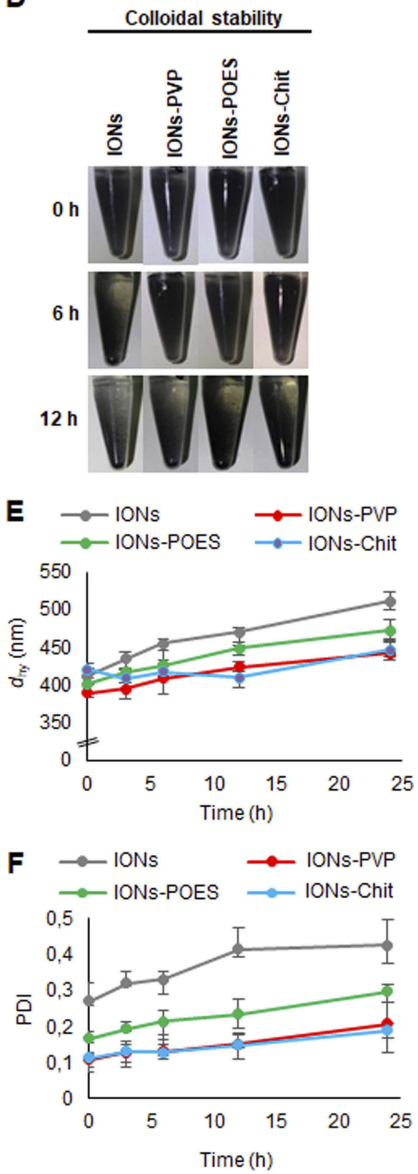

Figure I Surface coating of IONs with biocompatible surfactant (POES) or polymers (PVP and Chit). (A) Schematic representation of surface coating of bare IONs with PVP, POES and Chit with a consequent tethering of cytotoxic substances Dox and Elli using incubation or ultrasonication, respectively. (B) SEM micrographs of morphology of bare IONs and their morphology after surface coatings. The scale bars, $400 \mathrm{~nm}$ (left) or $5 \mu \mathrm{m}$ (right). (C) Content of organic matter in surface-coated formulations analyzed using $\mathrm{CHNS/O}$ analyzer. The values are expressed as the mean of three independent replicates $(n=3)$. Vertical bars indicate standard error. (D) Photodocumentation of a colloidal stability of bare and surface-coated IONs. Time-evolution of (E) $d_{\text {hy }}$ and (F) PDI, both analyzed in Ringer's solution. The values are expressed as the mean of six independent replicates $(n=6)$. The vertical bars + and - errors.

Abbreviations: IONs, iron oxide nanoparticles; POES, polyoxyethylene stearate; PVP, polyvinylpyrrolidone; Chit, chitosan; SEM, scanning electron microscopy; $d_{\text {hy }}$ hydrodynamic diameter; PDI, polydispersity index. 
ultrasonication $v s$ simple incubation. Interestingly, in some experiments, LE dependence on temperature exhibited a non-linear behavior, which is most likely due to a propensity of surface coatings to swell or shrink, directly affecting a portion of interaction sites for drug binding. ${ }^{28}$ However, to fully understand this phenomenon on a surface of IONs, further analyses might be done. Calculated LEs are shown in Figure 2A. It can be generalized that ultrasonication resulted in better LEs for both topo II poisons. On the other hand, both topo II poisons display distinct loading affinity to different surface coatings. The highest tethering of Dox was achieved using IONs-POES (LE 70\%, approx. $1.4 \mathrm{mg}$ Dox/ mg of IONs-POES), while Elli was best tethered to IONsPVP (LE $\sim 60 \%$, approx. $1.2 \mathrm{mg}$ Elli/mg of IONs-PVP). Finally, IONs-Chit bound only $20 \%$ of Dox and $30 \%$ of
Elli. It is also worth to note, that equal tests were carried out with bare IONs that bound approx. $45 \%$ of Elli and only $20 \%$ of Dox. SEM micrographs in Figure $2 \mathrm{~B}$ illustrate that the second application of ultrasound caused larger surface collisions and deformations resulting in the formation of smaller particles on IONs surface. This resulted in a slight increase in PDI and broadening of IONs $d_{\text {hy }}$ distribution (Figure 2C). Additionally, to predict a biological behavior of IONs, we performed incubation of bare and various surface-coated IONs with or without tethered topo II poisons in fully supplemented culture medium. Mean $\zeta$-potential values are summarized in Table 1. It was found that bare IONs exhibit only low medium stability, supporting the need for a proper surface coating. Noteworthy, in case of IONs with tethered topo II poisons, incubation in culture medium
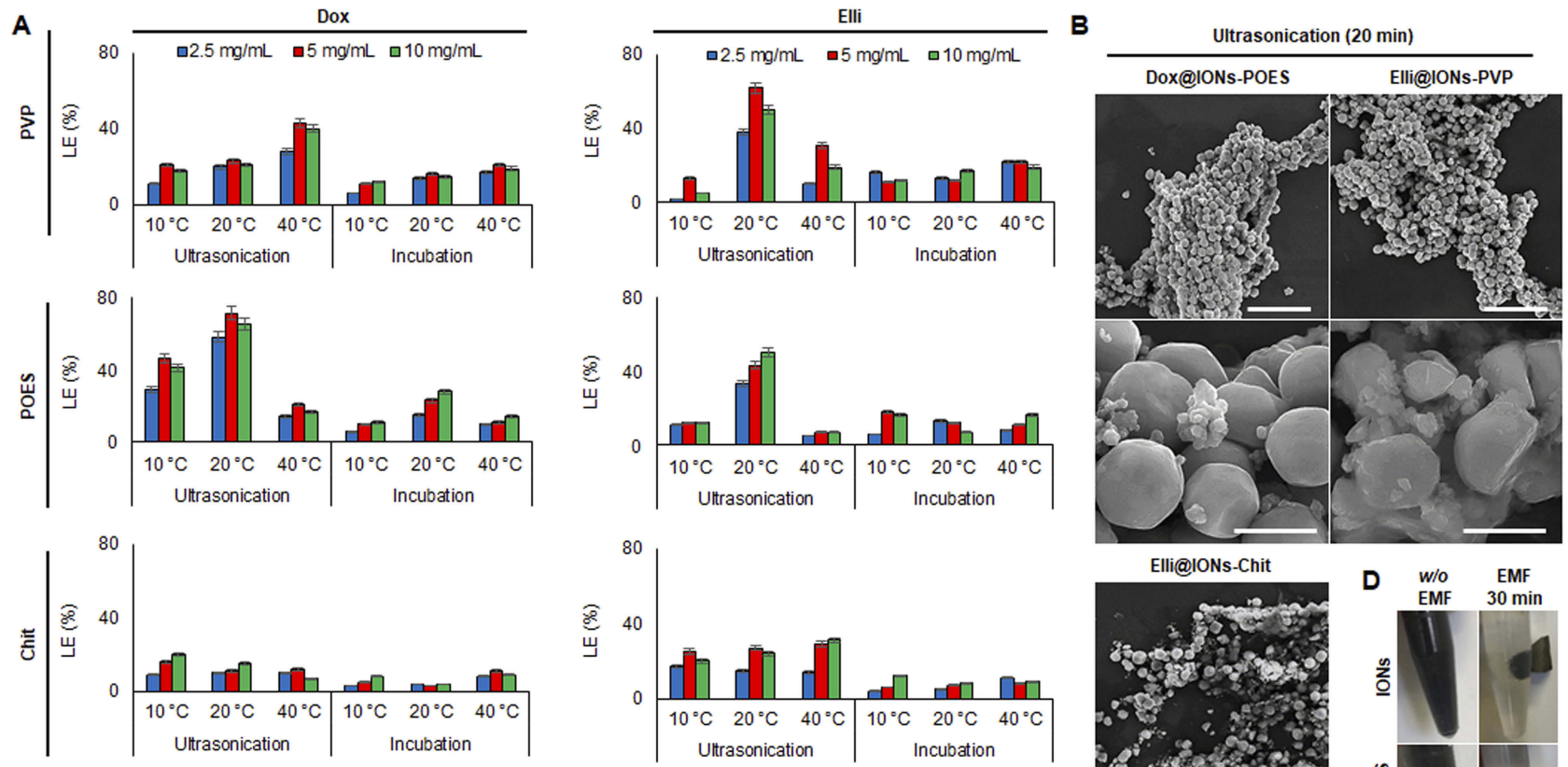
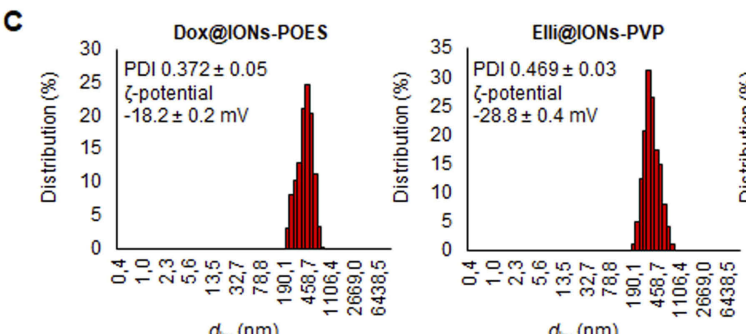

$d_{\text {iny }}(\mathrm{nm})$

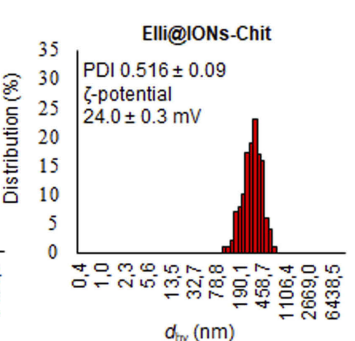

$d_{\text {iny }}(\mathrm{nm})$

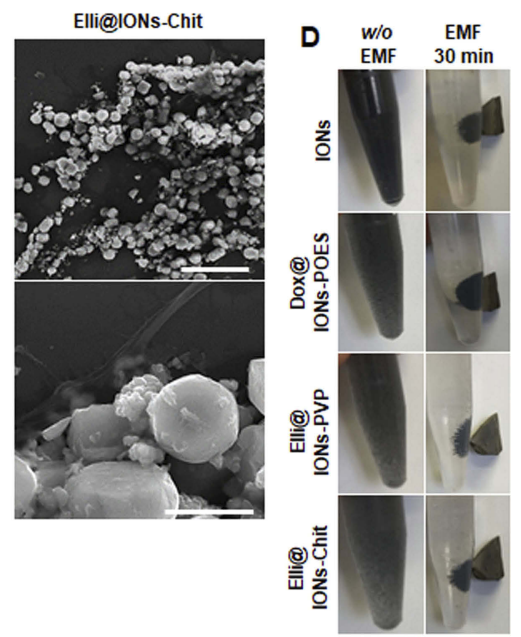

Figure 2 Optimization of loading of Dox and Elli onto surface-coated IONs. (A) Different amounts of surface-coating agents were tested for their LE with constant amounts for Dox and Elli $(2 \mathrm{mg} / \mathrm{mL})$. (B) SEM micrographs showing selected surface-coated IONs after 20 mins ultrasonication-mediated tethering of Dox or Elli. Scale bars, $5 \mu \mathrm{m}$ (top), $400 \mathrm{~nm}$ (bottom). (C) Distribution of $d_{\text {hy }}$ of Dox/Elli-loaded surface-modified IONs with the highest LEs. Inserted are PDI and $\zeta$-potential values of IONs dispersed in Ringer's solution. (D) Photographs of bare IONs and selected topo II poisons-tethered surface-coated IONs after the application of an EMF (Nd-Fe-B permanent magnet, 30 mins).

Abbreviations: IONs, iron oxide nanoparticles; LE, loading efficiency; Dox, doxorubicin; Elli, ellipticine; SEM, scanning electron microscopy; PDI, polydispersity index; EMF, external magnetic field. 
resulted in a slight alteration of $\zeta$-potentials (for comparison, see $\zeta$-potential values recorded in PBS inserted in Figure 2C). Lastly, it must be noted that upon tethering, IONs retained their ability to respond to EMF and after 30 mins all IONs are immobilized on EMF without obvious impurities in a solution (Figure 2D).

\section{In vitro release of topo II poisons}

The successful liberation of a drug in the target site is fundamental for each cancer-targeted delivery system. Thus, we analyzed the release kinetics of Dox and Elli in three environments, mimicking physiologically relevant environments. Cumulative release profiles revealed $\mathrm{pH}-$ responsive behavior, particularly for Elli@IONs-PVP and Dox@IONs-POES (Figure 3). Both formulations exhibited sustained release in acidic (endosomal, $\mathrm{pH}$ 5.0) buffer (85\% release of Elli and 55\% release of Dox after 24 hrs), which is significantly higher $(P<0.01)$ compared to release of Dox or Elli in plasma or neutral environments. Interestingly, bare IONs, IONs-Chit and IONs-POES were capable of relatively fast burst release of Dox or Elli in all three tested buffers, indicating weak interactions between drugs and nanomaterials.

\section{Cytotoxic activity}

We further performed a set of in vitro analyses to evaluate the cytotoxic effects of surface-coated IONs with tethered topo II poisons. Cytotoxicity was assayed on three different types of cells, malignant MDA-MB-231 and nonmalignant HBL-100 and HEK-293. 24hIC 50 values are summarized in Table 2.

Table I Mean $\zeta$-potential values of bare and surface-modified IONs upon incubation in fully supplemented culture medium (RPMI-I640 with $10 \%$ of FBS)

\begin{tabular}{|l|l|}
\hline Sample & $\zeta$-potential (mV \pm SD) \\
\hline Bare IONs & $-9.02 \pm 0.3$ \\
IONs-POES & $-23.2 \pm 0.4$ \\
IONs-PVP & $-25.5 \pm 0.1$ \\
IONs-Chit & $32.9 \pm 0.5$ \\
Dox@IONs-POES & $-16.6 \pm 0.3$ \\
Elli@IONs-PVP & $-12.2 \pm 0.1$ \\
Elli@IONs-Chit & $14.0 \pm 0.4$ \\
\hline
\end{tabular}

Notes: Prior analysis, samples were incubated in fully supplemented culture medium (RPMI-1640 with 10\% FBS). $\zeta$-potential values are means of three independent experiments $(n=3)$.

Abbreviations: IONs, iron oxide nanoparticles; PVP, polyvinylpyrrolidone; POES, polyoxyethylene stearate; Chit, chitosan; Dox, doxorubicin; Elli, ellipticine.
Overall, MDA-MB-231 cells were more susceptible to Dox and Elli, which corresponds to their faster proliferation rate. In opposite, surface-coated IONs without tethered drugs caused only negligible cytotoxic effects in extremely high concentrations. The highest cytotoxicity found for IONs-Chit could be attributed to their positive surface charge ( $\zeta$-potential $31.1 \pm 0.4 \mathrm{mV}$ ) causing cytotoxic effects by interacting with negatively charged membranes. ${ }^{29}$ Interestingly, relatively low cytotoxicity was found for Dox@IONs-Chit. We anticipate that this is due to a strong binding of Dox onto the IONs-Chit surface as demonstrated in Figure 3. Among the most potent nanoformulations belonged Dox@IONs-POES and Elli@IONs-PVP, which also exhibited very good LEs and release kinetics profiles. Therefore, these two variants were employed for further analyses. Since in some treatments, surfacecoated IONs nanoformulations displayed lower $24 \mathrm{hIC}_{50}$ values than free drugs, we evaluated possible synergistic effects using the Chou-Talalay method. ${ }^{26}$ The determined CIs demonstrate that IONs-POES possesses synergistic effects to Dox in MDA-MB-231 cells (CI 0.692). In other surface-coated IONs formulations, the effects were more additive (CI=1.0, Elli@IONsPVP in MDA-MB-231) or slightly antagonistic (CI $>1.0$, both nanoformulations in all tested non-malignant cells). This phenomenon was corroborated by the normalized isobolograms shown in Figure 4A. As a follow-up of these findings, analysis of internalization was performed through quantitation of total intracellular iron in cells treated with bare IONs (both, unsonicated and sonicated), Dox@IONs-POES and Elli@IONs-PVP. Interestingly, in contrast to nonmalignant HEK-293 and HBL-100 cells, MDA-MB231 cells displayed the highest capability to internalize IONs irrespective on the surface functionalization (Figure 4B). In addition, we found that all cell lines accumulate a higher content of iron upon incubation with bare-sonicated IONs (compared to their unsonicated counterparts). This highlights the fact that smaller particles formed during sonochemical steps markedly contribute to the amount of total intracellular iron. CLSM analyses revealed that malignant MDAMB-231 cells display the fastest uptake capability for both, Dox@IONs-POES and Elli@IONs-PVP, and after $6 \mathrm{hrs}$ upon treatment, topo II poisons are present in nuclei (Figure 4C). 

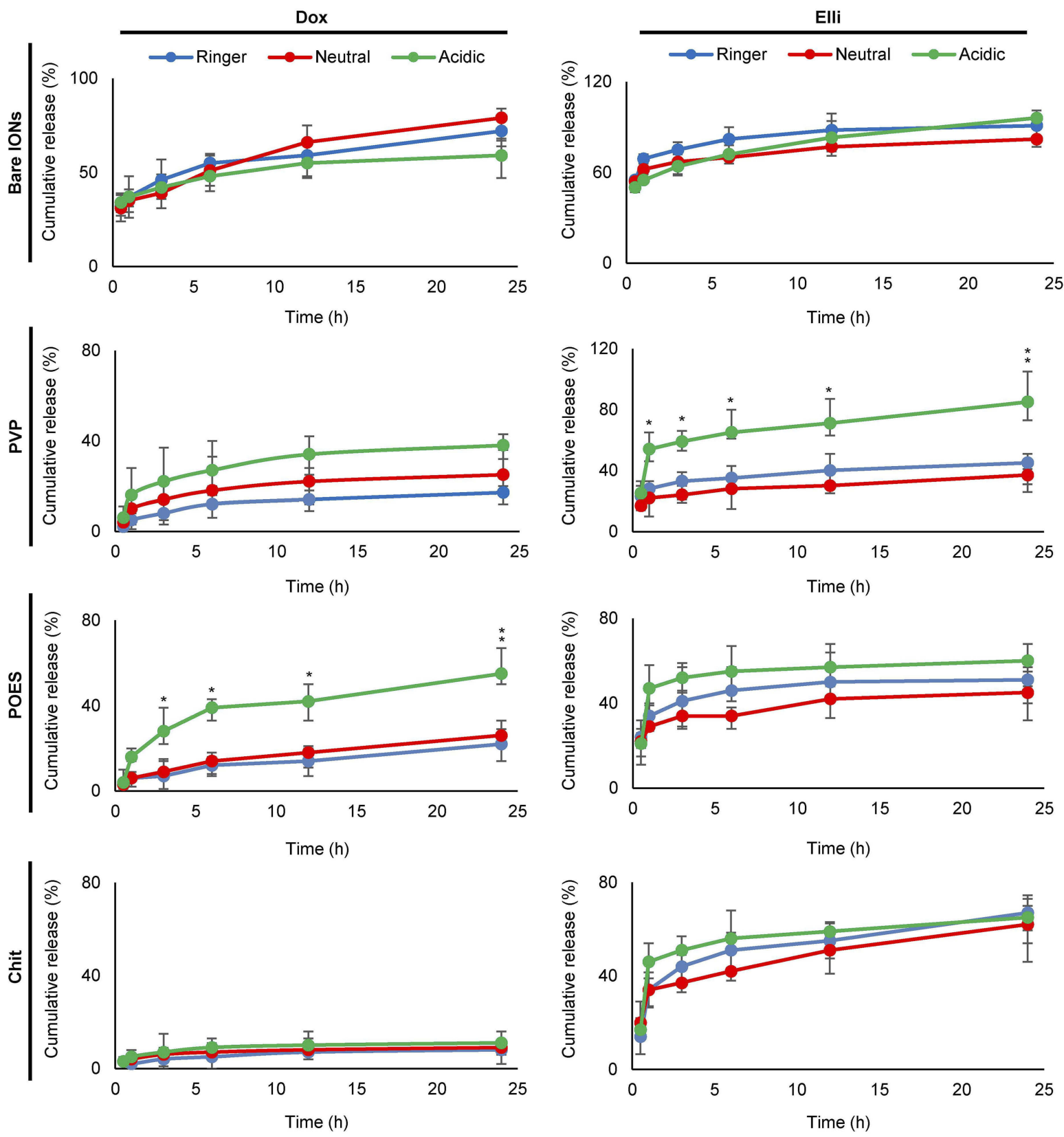

Figure 3 In vitro cumulative release kinetic profiles of Dox and Elli from bare and surface-coated IONs determined in various physiological $\mathrm{pH}$ conditions (intracellular, $\mathrm{pH}$ 6.9, endosomal, $\mathrm{pH} 5.0$ and plasma, $\mathrm{pH}$ 7.4). The values are expressed as the mean of six independent replicates $(\mathrm{n}=6)$. Vertical bars indicate + and - errors. The $p$-values were calculated for each time-point and denoted if found to be significantly different, $* P<0.05, * * P<0.01$.

Abbreviations: Dox, doxorubicin; Elli, ellipticine; IONs, iron oxide nanoparticles.

\section{Anti-migratory activity and mechanism of action}

Cell migration is among the major biological characteristics of malignant cells. Therefore, we examined the effect of Dox@IONs-POES and Elli@IONs-PVP on a migration of all three tested cell types (representative micrographs are shown in Figure 5A). Interestingly, in agreement with cytotoxic and internalization analyses, the highest anti- migratory activity was found in MDA-MB-231 (Figure 5B). Contrary to that, the lowest inhibitory effect was found for non-malignant HBL-100 cells. Since topo II poisons induce DNA cleavage, ${ }^{19}$ we further carried out SCGE to quantify the DNA fragmentation due to Dox@IONsPOES and Elli@IONs-PVP exposure (Figure 5C). As shown in Figure 5D, both nanoformulations caused extensive DNA fragmentation (comet grades 3 and 4) in MDA- 
Table 2 24lhC 50 values for topo II poisons IONs nanoformulations

\begin{tabular}{|c|c|c|}
\hline Treatment & Cell line & $24 \mathrm{hIC} \mathrm{C}_{50}(\mu \mathrm{g} / \mathrm{mL})$ \\
\hline \multirow[t]{3}{*}{ IONs-PVP } & MDA-MB-23I & $891.93 \pm 16.11$ \\
\hline & HEK-293 & $736.18 \pm 10.67$ \\
\hline & HBL- 100 & $779.05 \pm 13.00$ \\
\hline \multirow[t]{3}{*}{ IONs-POES } & MDA-MB-23I & $632.64 \pm|2.3|$ \\
\hline & HEK-293 & $765.17 \pm 7.69$ \\
\hline & HBL- 100 & $711.16 \pm 15.11$ \\
\hline \multirow[t]{3}{*}{ IONs-Chit } & MDA-MB-23I & $423.28 \pm 8.11$ \\
\hline & HEK-293 & $499.79 \pm 6.20$ \\
\hline & HBL- 100 & $444.08 \pm 5.03$ \\
\hline \multirow[t]{3}{*}{ Dox } & MDA-MB-23I & $6.38 \pm 1.12$ \\
\hline & HEK-293 & $8.74 \pm 0.94$ \\
\hline & HBL- 100 & $10.03 \pm 1.70$ \\
\hline \multirow[t]{3}{*}{ Dox@IONs-PVP } & MDA-MB-23I & $|2.3| \pm|.6|$ \\
\hline & HEK-293 & $|4.2| \pm 0.77$ \\
\hline & HBL- 100 & $22.09 \pm 2.02$ \\
\hline \multirow[t]{3}{*}{ Dox@IONs-POES } & MDA-MB-23I & $3.19 \pm 0.11$ \\
\hline & HEK-293 & $9.96 \pm 1.08$ \\
\hline & HBL- 100 & $16.01 \pm 2.95$ \\
\hline \multirow[t]{3}{*}{ Dox@IONs-Chit } & MDA-MB-23I & $76.19 \pm 4.00$ \\
\hline & HEK-293 & $84.6 I \pm 3.14$ \\
\hline & HBL- 100 & $89.43 \pm 2.97$ \\
\hline \multirow[t]{3}{*}{ Elli } & MDA-MB-23I & $3.76 \pm 0.22$ \\
\hline & HEK-293 & $4.49 \pm 1.31$ \\
\hline & HBL- 100 & $4.05 \pm 0.92$ \\
\hline \multirow[t]{3}{*}{ Elli@IONs-PVP } & MDA-MB-23I & $4.19 \pm 1.08$ \\
\hline & HEK-293 & $11.67 \pm 2.19$ \\
\hline & HBL- 100 & $9.37 \pm 0.99$ \\
\hline \multirow[t]{3}{*}{ Elli@IONs-POES } & MDA-MB-23I & $8.67 \pm 2.11$ \\
\hline & HEK-293 & $15.33 \pm 3.09$ \\
\hline & HBL- 100 & $9.80 \pm 0.97$ \\
\hline \multirow[t]{3}{*}{ Elli@IONs-Chit } & MDA-MB-23I & $|3.6| \pm 1.0 \mid$ \\
\hline & HEK-293 & $11.07 \pm 2.76$ \\
\hline & HBL- 100 & $19.33 \pm 1.94$ \\
\hline
\end{tabular}

Notes: Cells exposed to different concentrations of Dox or Elli-loaded surfacecoated IONs were assayed for viability by XTT assay at $24 \mathrm{hrs}$ and $24 \mathrm{hIC} 50$ values were calculated using GraphPad Prism 5 software (GraphPad Software, Inc., La Jolla, CA, USA). The applied concentrations were normalized using the intrinsic fluorescence of Dox and Elli. Surface-coated IONs without bound cytotoxic agents were normalized to the total iron using AAS. $24 \mathrm{hIC}_{50}$ values are means of six independent experiments ( $n=6$, mean \pm standard error).

Abbreviations: Dox, doxorubicin; Elli, ellipticine; IONs, iron oxide nanoparticles; PVP, polyvinylpyrrolidone; POES, polyoxyethylene stearate; Chit, chitosan; XTT, 2,3bis-(2-methoxy-4-nitro-5-sulfophenyl)-2H-tetrazolium-5-carboxanilide; AAS, atomic absorption spectrometry.

MB-231 cells, in which almost complete fragmentation was found. In contrast, a higher number of lower grade comets was observed in HEK-293 and HBL-100 cells. This phenomenon corroborates a partial selectivity of surface-coated
IONs nanoformulations of topo II poisons to malignant MDA-MB-231 cells. Thus, whole-cell lysates of these cells were investigated to identify possible effects of IONs on crucial regulatory proteins. Figure $5 \mathrm{E}$ illustrates that both nanoformulations are capable to decrease the amount of executioner procaspase-3. Despite both, Dox and Elli are capable to induce oxidative stress and IONs presence could plausibly lead to a deregulation of metal homeostasis, ${ }^{30-32}$ no effect on the expression of MT-1/2 or MT-3 was found. Moreover, similar to free Dox, Dox@IONs-POES and Elli@IONs-PVP caused slight enhancement of p53 expression.

\section{In vitro biocompatibility}

In general, for use in vivo settings, nanomaterials should not interact with blood elements. To delineate this phenomenon, we investigated the possible hemolytic effects of Dox and Elli tethered to surface-coated IONs. Figure 6A shows that both nanoformulations induced a dose-dependent hemolytic response of human RBCs. The highest applied concentrations caused 42\% (Dox@IONs-POES) or 27\% (Elli@IONs-PVP), respectively. It is worth noting that lower concentrations induced acceptable rate of hemolysis $(\sim 5 \%) .{ }^{33}$ Moreover, hemolysis induced by IONs-PVP and IONs-POES without tethered topo II poisons was comparable to that of PBS. Another pivotal aspect of hemocompatibility is nanomaterial-blood proteins interaction. Hence, we further investigated rate of adsorption of plasma proteins (referred to as protein corona) on the IONs surface. Figure $6 \mathrm{~B}$ shows that despite bare IONs form extensive protein corona, surface coating with POES and PVP is capable to markedly inhibit this phenomenon. Interestingly, Elli-IONsPVP formed corona pattern similar to bare IONs. This can be explained by a disruption of PVP coating due to a second sonochemical modification step required for Elli tethering. Finally, we evaluated the binding of C3 that can trigger a nanoparticles engulfment by leukocytes and macrophages through complement receptors and consequent recruitment of inflammatory cells and anaphylaxis. ${ }^{34,35}$ Figure $6 \mathrm{C}$ shows that no $\alpha$ chain fragment of $\mathrm{C} 3 \mathrm{~b}$ was bound on the IONs surface, which is in line with no or only negligible formation of protein corona, considered as a crucial prerequisite for opsonization of nanomaterials. ${ }^{36}$

\section{Discussion}

IONs have attracted a great deal of attention in nanomedicine over the past decade. Their unique properties allow 
A
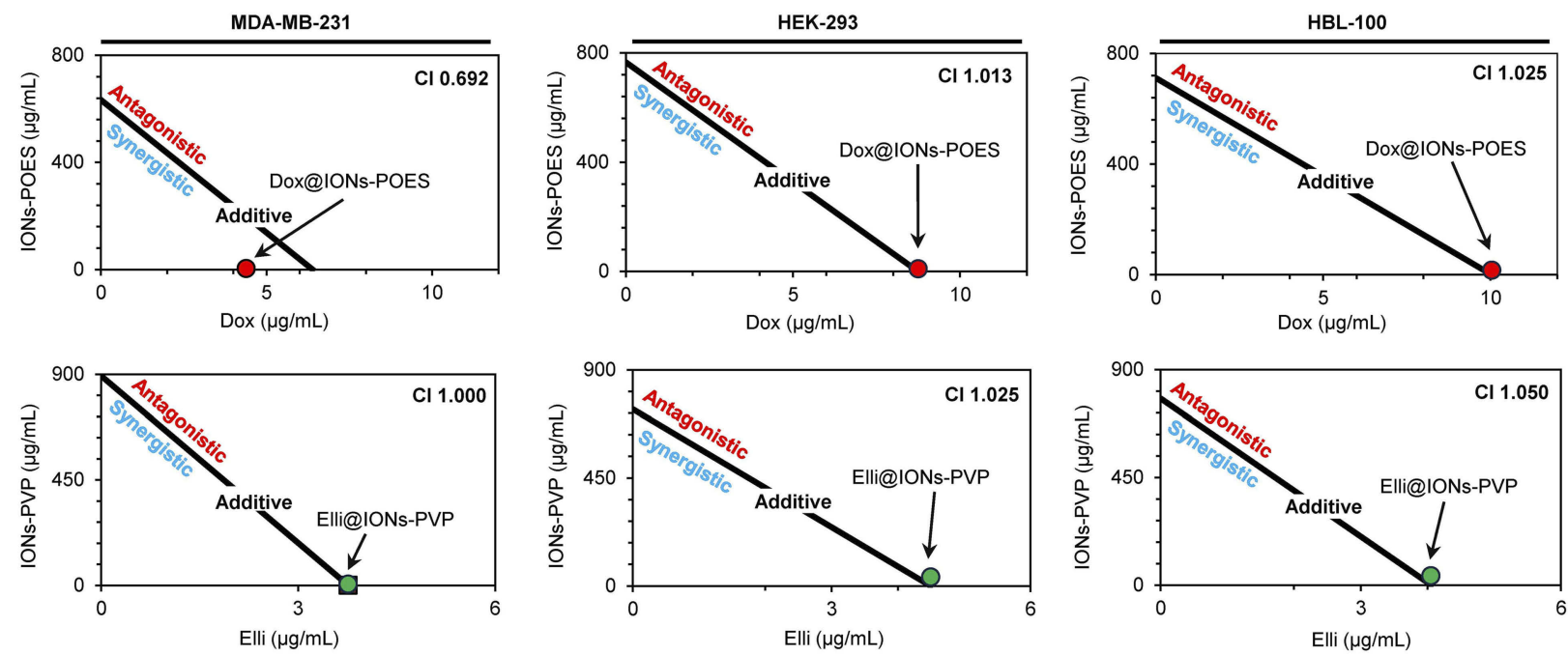

B

C
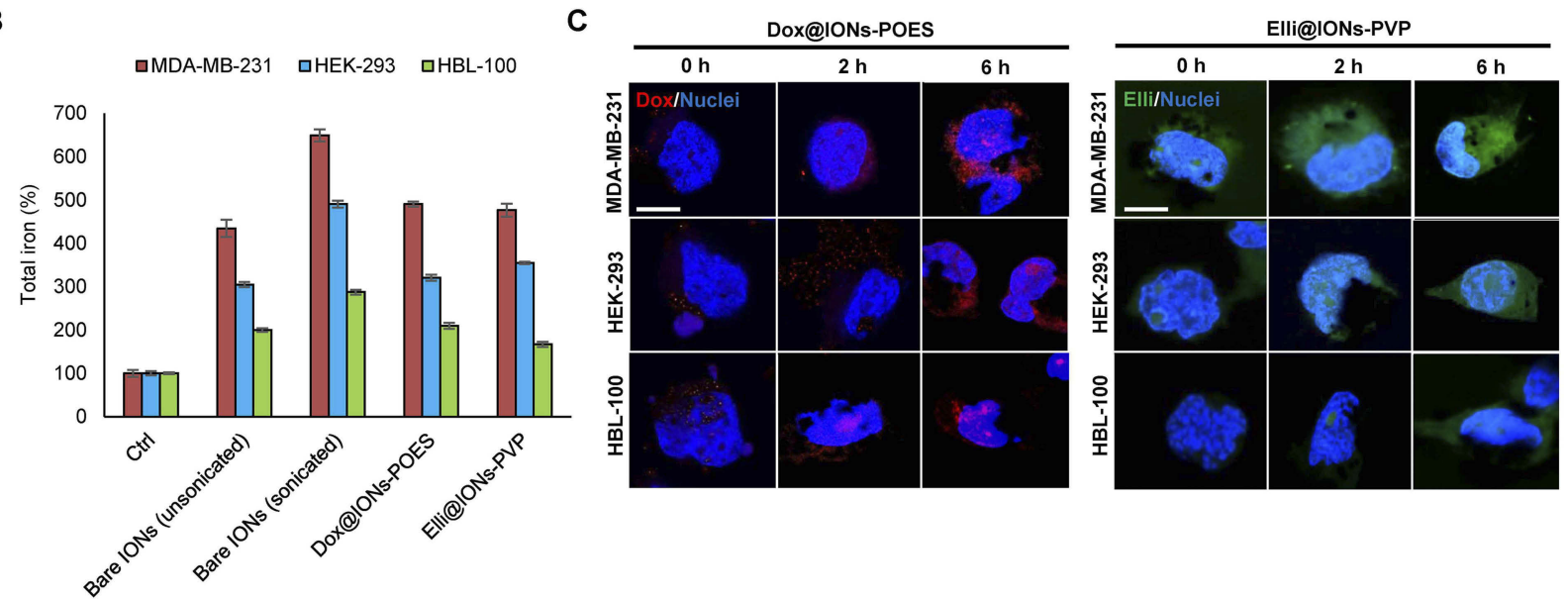

Figure 4 Evaluation of potential synergic effects of IONs to Dox and Elli cytotoxicity. (A) Isobolograms demonstrating synergistic/antagonistic effects of selected surfacecoated IONs and Dox/Elli within all tested cell lines. (B) Total iron accumulation in intracellular region of treated cells (6 hrs) analyzed by AAS. The values are expressed as the mean of three independent replicates $(n=3)$. The vertical bars indicate standard error. $(\mathbf{C})$ Internalization kinetics of Dox@IONs-POES and Elli@IONs-PVP analyzed using CLSM in all tested cell lines during the first 6 hrs of treatment. Scale bar, $15 \mu \mathrm{m}$.

Abbreviations: Dox, doxorubicin; Elli, ellipticine; IONs, iron oxide nanoparticles; AAS, atomic absorption spectroscopy; CLSM, confocal laser scanning microscopy; Cl, combination index.

them for applications including magnetic resonance imaging, magnetic fluid hyperthermia or magnetic drug delivery vehicles. ${ }^{3-6,37}$ Among other superb intrinsic properties, a capability for simple surface functionalization makes IONs exceptional candidates for a tailoring of drug-specific delivery vehicles. Therefore, in the present study, we aimed at the synthesis and ultrasound-mediated surface coating of IONs toward a loading and sustained release of topo II poisons Dox and Elli.

Bare IONs prepared by oxidizing $\mathrm{Fe}(\mathrm{OH})_{2}$ gel in the presence of $\mathrm{KNO}_{3}{ }^{24}$ were surface-coated with three different polymers/surfactant (PVP, POES, Chit), known for their biocompatibility, biodegradability and ability to enhance the solubility of drugs. ${ }^{38,39}$ Coating agents were deposited through ultrasound that generates acoustic cavitation, which impacts the solid surface of IONs and causes mechanical collisions ${ }^{40}$ observable in SEM micrographs in Figures $1 \mathrm{~B}$ and 2B. Despite the collisions could have deleterious effects on nanomaterials, we found that upon coating, IONs exhibited good colloidal stability, which can be attributed to an effective repulsive force caused by organic coatings. $^{41}$

Apart from the sonochemical deposition of organic coatings, we evaluated the efficiency of ultrasound-mediated tethering of Dox and Elli and compared this approach with the loading of topo II poisons through a continuous agitation. Indeed, we found that a second-step of sonochemical modification resulted in pronouncedly higher LEs for 

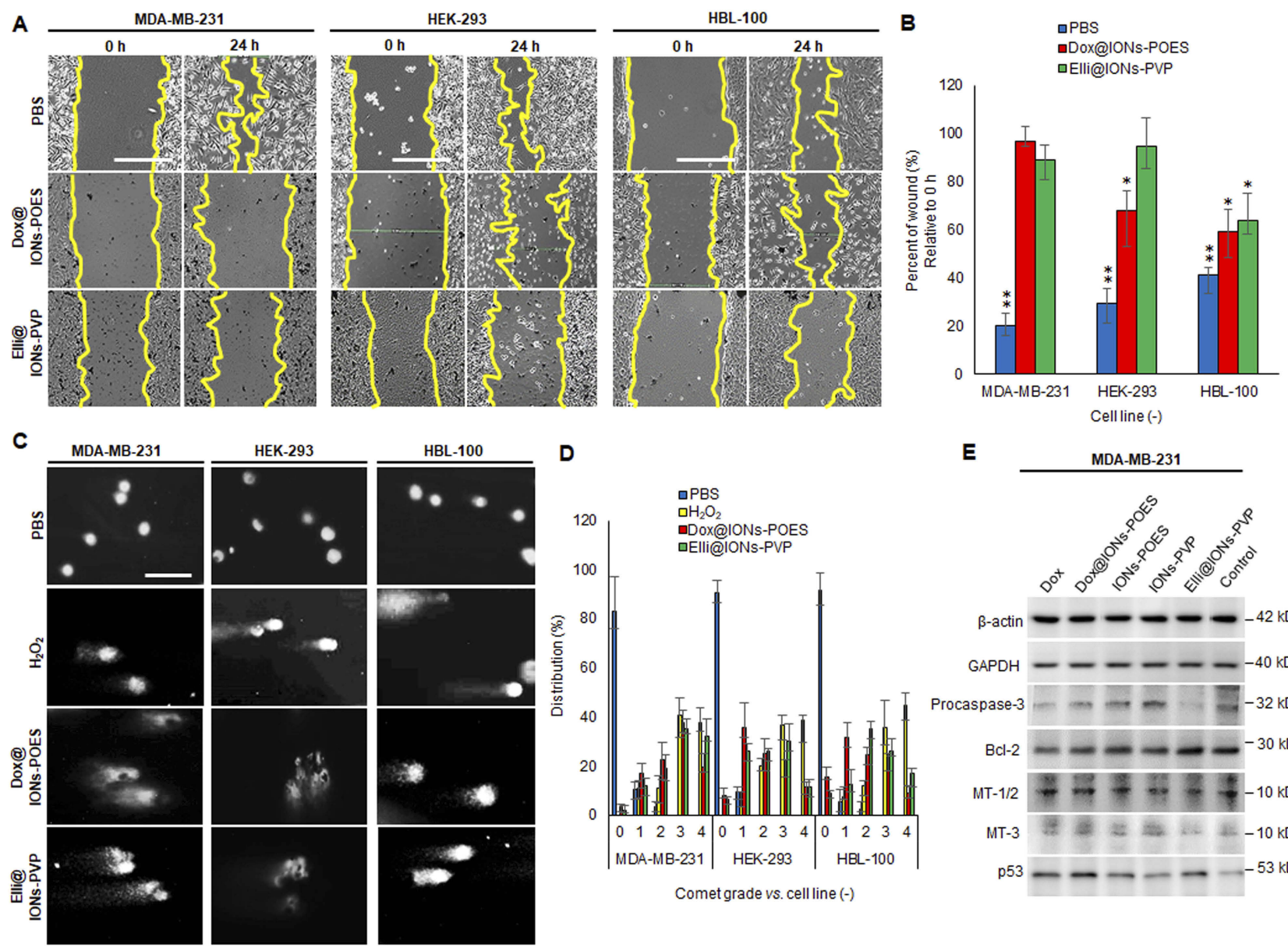

Figure 5 (A) Representative micrographs of wound-healing assay showing the marked effect of Dox/Elli-tethered surface-modified IONs on a migration of tested cell lines. Representative pictures demonstrate the artificial gaps at the experimental start-point ( $0 \mathrm{hrs})$ and migration of cells after 24 hrs cultivation. Yellow lines indicate the approximate borders of the initial gap. Scale bar, $400 \mu \mathrm{m}$. (B) Quantitation of relative free areas from wound-healing assay. The values are expressed as the mean of three independent replicates $(n=3)$. Vertical bars indicate + and -errors. $* P<0.05$, $* * P<0.01$ related to the initial gap area. (C) SCGE of cells following exposure to Dox@IONsPOES and Elli@IONs-PVP. PBS ( $\mathrm{pH} 7.4$ ) and $60 \mu \mathrm{M} \mathrm{H} \mathrm{H}_{2} \mathrm{O}_{2}$ were employed as negative and positive controls. Scale bar, $100 \mu \mathrm{m}$. (D) Quantitation of index of damage upon I2 hrs exposure. The values are expressed as the mean of three independent replicates $(n=3)$. Vertical bars indicate + and - errors. (E) Representative immunoblots of wholecell lysate of MDA-MB-23I cells. $\beta$-Actin and GAPDH served as loading controls.

Abbreviations: Dox, doxorubicin; Elli, ellipticine; IONs, iron oxide nanoparticles; SCGE, single-cell gel electrophoresis; PBS, phosphate-buffered saline; GAPDH, glyceraldehyde-3-phosphate dehydrogenase.

Dox and Elli. Although this process was accompanied by additional collisions of IONs and formation of small fragments, resulting nanoformulations of Dox and Elli exhibited relatively narrow size distribution and fast response to EMF. Despite the specific mechanism responsible for enhanced LEs due to ultrasonication are not known, we anticipate that surface collisions and incurred debris increased the binding surface for loading of topo II poisons. ${ }^{42}$ Since bare IONs did not reach comparable LEs for both topo II poisons, surface coatings are obviously crucial for this process. Noteworthy, both IONs-POES and IONS-PVP were capable to load sufficient amounts of Dox and Elli, which is in good agreement with previously published studies. ${ }^{38,43}$ Interestingly, despite IONs-Chit exhibited the highest amount of surface organic matter, considerably lower LEs were achieved for both topo II poisons. Moreover, due to unfavorable cumulative release profiles, IONs-Chit was excluded from further experiments.

Despite we did not investigated the chemical interactions responsible for efficient drug loadings to IONs-PVP and IONs-POES, based on the available literature, we anticipate that hydrazine moiety of PVP forms hydrazone bonds with ketonic groups of Dox. ${ }^{44}$ Since Elli is poorly water-soluble compound, we hypothesize that presence of both, PVP or POES increases its solubility and promotes the biding to surface-coated IONs. ${ }^{45}$ However, to prove this, additional investigations might be done. Importantly, we found that Dox@IONs-POES and Elli@IONs-PVP exhibited strong 
A

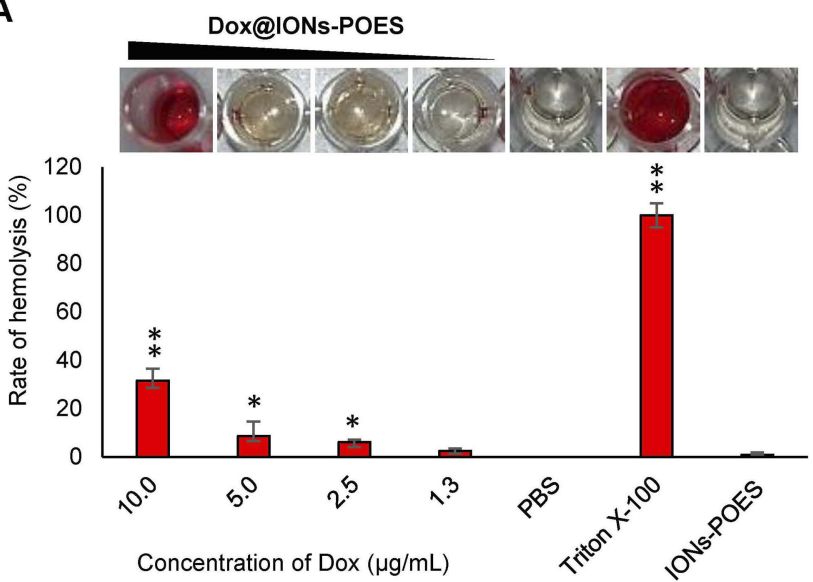

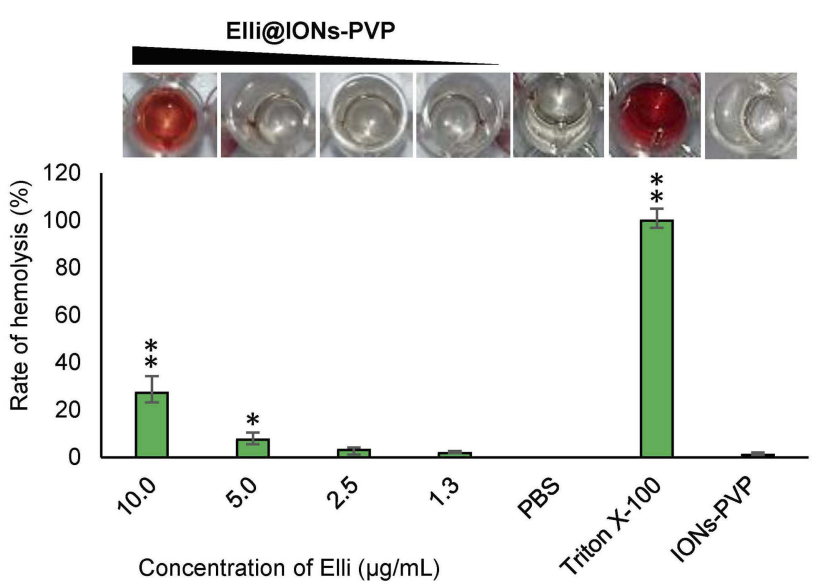

Concentration of Elli $(\mu \mathrm{g} / \mathrm{mL})$
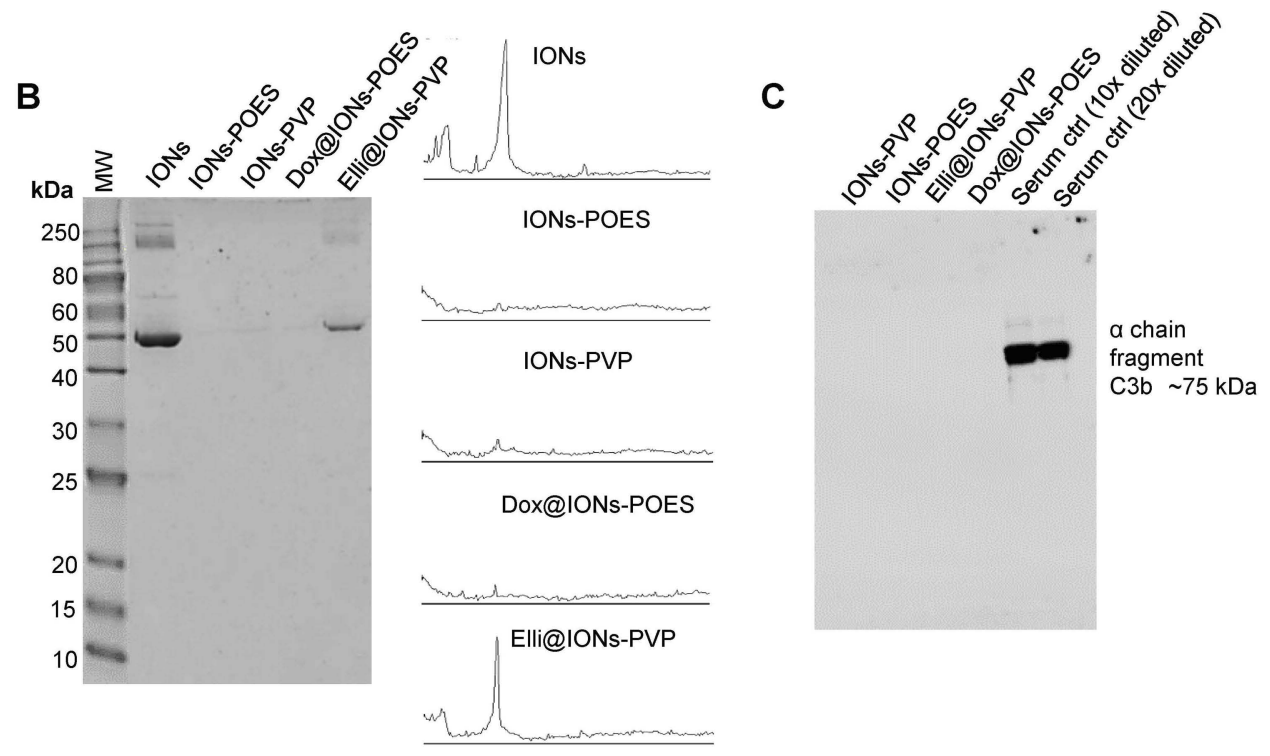

Figure 6 Examination of in vitro biocompatibility of Dox@IONs-POES and Elli@IONs-PVP. (A) Hemolysis of Dox@IONs-POES and Elli@IONs-PVP assayed on human RBCs. PBS ( $\mathrm{pH} 7.4)$ and $0.1 \%$ Triton X-100 were utilized as negative and positive controls, respectively. Amount of tested IONs-POES and IONs-PVP without tethered Dox and Elli is adequate to the highest amount of IONs in Dox@IONs-POES and Elli@IONs-PVP treatments. Upper images depict representative photographs of tested samples. The values are expressed as the mean of three independent replicates $(n=3)$. Vertical bars indicate + and - errors. $* P<0.05$, $* * P<0.0 I$ related to the IONs-POES and IONs-PVP without tethered topo II poisons. (B) Protein corona patterns obtained after 30 mins incubation of annotated formulations with human plasma followed by extensive washing, elution, and loading onto I $\%$ SDS-PAGE. As a control, human plasma ( $1,000 \times$ diluted) was loaded to the first lane. Figures on the right side show protein coronas quantified by densitometric analysis. (C) Immunoblot of $\mathrm{C} 3 \mathrm{~b}$ binding from human serum from male $A B$ clotted whole blood.

Abbreviations: Dox, doxorubicin; Elli, ellipticine; IONs, iron oxide nanoparticles; RBCs, red blood cells.

pH-responsive drug release, which may facilitate burst in endosomes or near the acidic tumor microenvironment. ${ }^{46}$

In our in vitro experiments, we found some cell typedependent differences affecting surface-coated IONs uptake and subsequent cytotoxicity. In all assays, we found that malignant rapidly proliferating MDA-MB-231 cells are more susceptible to topo II poisons tethered IONs compared to nonmalignant HBL-100 and HEK-293. A plausible explanation is that cancer cells generally elaborate mechanisms to enhance endocytosis and macropinocytosis, ${ }^{47,48}$ which are known to be responsible for IONs internalization. ${ }^{49}$ Additionally, cancer cells are characterized by a higher membrane fluidity compared to non-malignant cells. ${ }^{50,51}$ This fact was supported by a markedly enhanced accumulation of intracellular iron, particularly for sonicated IONs consisting of a population of smaller particles resulting from sonochemistry-triggered collisions of IONs cores (Figure 4B). Upon internalization, surfacecoated IONs nanoformulations retained the known cytotoxic effects caused by topo II poisons as evidenced by an array of analyses including analysis of migration, proliferation and of quantitation of DNA fragmentation. ${ }^{20}$ Moreover, decrease in expression of executioner procaspase- 3 together with a slight enhancement of expression of p53 indicates an activation of apoptotic pathways. ${ }^{52}$ 
Generally, polymeric/surfactant surface coating produces biocompatible hybrid materials. ${ }^{53}$ Remarkably, the biocompatibility analyses revealed that topo II tethered surface-coated IONs are pronouncedly hemocompatible and inert against the formation of protein corona (surface adsorption of plasma proteins). These properties have extraordinary importance for further translation of testing to preclinical in vivo models. We are eager to continue with this plan in future studies.

\section{Conclusion}

In summary, we have demonstrated that surface of bare IONs can be simply functionalized through an ultrasound-mediated deposition of organic compounds (PVP, POES or Chit) and subsequent tethering of topo II poisons (Dox and Elli). Despite two-step sonochemical modification pipeline causes surface collisions, surface-coated IONs are capable to bind significant amounts of Dox and Elli, and to enable for their sustained release kinetics in slightly acidic $\mathrm{pH}$, mimicking tumor hypoxia or endosomes. Additionally, surface-coated IONs exhibited synergistic or additive effects to the cytotoxicity of topo II poisons in malignant MDA-MB-231 cells, while slightly antagonistic effects in non-malignant HBL-100 and HEK-293 cells. Furthermore, due to surface coatings, IONs nanoformulations exhibited good biocompatibility in vitro. These findings could support the development of biocompatible delivery systems for topo II poisons to enhance their therapeutic efficiency.

\section{Acknowledgment}

Financial support from the Czech Health Research Council (AZV project No. 15-28334A), AF-IGA-IP-2018/007 and CEITEC 2020 (LQ1601) with financial support from the Ministry of Education, Youth and Sports of the Czech Republic under the National Sustainability Programme II is gratefully acknowledged. We thank Milica Gagic for performing organic element analyses and all co-authors for their contribution.

\section{Disclosure}

The authors report no conflicts of interest in this work.

\section{References}

1. Bobo D, Robinson KJ, Islam J, Thurecht KJ, Corrie SR. Nanoparticlebased medicines: a review of FDA-approved materials and clinical trials to date. Pharm Res. 2016;33(10):2373-2387. doi:10.1007/ s11095-016-1958-5
2. Skorjanc T, Benyettou F, Olsen JC, Trabolsi A. Design of organic macrocycle-modified iron oxide nanoparticles for drug delivery. Chem Eur J. 2017;23(35):8333-8347. doi:10.1002/chem.201605246

3. Chertok B, Moffat BA, David AE, et al. Iron oxide nanoparticles as a drug delivery vehicle for MRI monitored magnetic targeting of brain tumors. Biomaterials. 2008;29(4):487-496. doi:10.1016/j. biomaterials.2007.08.050

4. Zhao Z, Zhou Z, Bao J, et al. Octapod iron oxide nanoparticles as high-performance $\mathrm{T}(2)$ contrast agents for magnetic resonance imaging. Nat Commun. 2013;4:2266. doi:10.1038/ncomms3266

5. Eguchi H, Umemura M, Kurotani R, et al. A magnetic anti-cancer compound for magnet-guided delivery and magnetic resonance imaging. Sci Rep. 2015;5:14. doi:10.1038/srep09194

6. Wahajuddin AS. Superparamagnetic iron oxide nanoparticles: magnetic nanoplatforms as drug carriers. Int J Nanomed. 2012;7:34453471. doi:10.2147/IJN.S30320

7. Quan QM, Xie J, Gao HK, et al. HSA coated iron oxide nanoparticles as drug delivery vehicles for cancer therapy. Mol Pharm. 2011;8(5):16691676. doi: $10.1021 / \mathrm{mp} 200006 \mathrm{f}$

8. Rosenblum D, Joshi N, Tao W, Karp JM, Peer D. Progress and challenges towards targeted delivery of cancer therapeutics. Nat Commun. 2018;9:12. doi:10.1038/s41467-018-03705-y

9. Xie J, Lee S, Chen XY. Nanoparticle-based theranostic agents. Adv Drug Deliv Rev. 2010;62(11):1064-1079. doi:10.1016/j.addr.2010.07.009

10. Ulbrich K, Hola K, Subr V, Bakandritsos A, Tucek J, Zboril R. Targeted drug delivery with polymers and magnetic nanoparticles: covalent and noncovalent approaches, release control, and clinical studies. Chem Rev. 2016;116(9):5338-5431. doi:10.1021/acs.chemrev. 5 b00589

11. Yang XQ, Grailer JJ, Rowland IJ, et al. Multifunctional SPIO/DOXloaded wormlike polymer vesicles for cancer therapy and MR imaging. Biomaterials. 2010;31(34):9065-9073. doi:10.1016/j.biomaterials. 2010.08.039

12. Unterweger H, Tietze R, Janko C, et al. Development and characterization of magnetic iron oxide nanoparticles with a cisplatin-bearing polymer coating for targeted drug delivery. Int $J$ Nanomed. 2014;9:3659-3676. doi:10.2147/IJN.S63433

13. Hamley IW. Nanotechnology with soft materials. Angew Chem Int Edit. 2003;42(15):1692-1712. doi:10.1002/anie.200200546

14. Jain TK, Foy SP, Erokwu B, Dimitrijevic S, Flask CA, Labhasetwar $\mathrm{V}$. Magnetic resonance imaging of multifunctional pluronic stabilized iron-oxide nanoparticles in tumor-bearing mice. Biomaterials. 2009;30(35):6748-6756. doi:10.1016/j.biomaterials.2009.08.042

15. Khandhar AP, Keselman P, Kemp SJ, et al. Evaluation of PEG-coated iron oxide nanoparticles as blood pool tracers for preclinical magnetic particle imaging. Nanoscale. 2017;9(3):1299-1306. doi:10.10 39/c6nr08468k

16. Kayal S, Ramanujan RV. Doxorubicin loaded PVA coated iron oxide nanoparticles for targeted drug delivery. Mater Sci Eng C-Mater Biol Appl. 2010;30(3):484-490. doi:10.1016/j.msec.2010.01.006

17. Mulens-Arias V, Rojas JM, Perez-Yague S, Morales MP, Barber DF. Polyethylenimine-coated SPIONs trigger macrophage activation through TLR-4 signaling and ROS production and modulate podosome dynamics. Biomaterials. 2015;52:494-506. doi:10.1016/j.biomaterials. 2015.02.068

18. Kalfalah FM, Mielke C, Christensen MO, Baechler S, Marko D, Boege F. Genotoxicity of dietary, environmental and therapeutic topoisomerase II poisons is uniformly correlated to prolongation of enzyme DNA residence. Mol Nutr Food Res. 2011;55:S127-S142. doi:10.1002/mnfr.201000509

19. Nitiss JL. Targeting DNA topoisomerase II in cancer chemotherapy. Nat Rev Cancer. 2009;9(5):338-350. doi:10.1038/nrc2607

20. Mistry AR, Felix CA, Whitmarsh RJ, et al. DNA topoisomerase II in therapy-related acute promyelocytic leukemia. $N$ Engl $J$ Med. 2005;352(15):1529-1538. doi:10.1056/NEJMoa042715 
21. Lyu YL, Kerrigan JE, Lin CP, et al. Topoisomerase II beta-mediated DNA double-strand breaks: implications in doxorubicin cardiotoxicity and prevention by dexrazoxane. Cancer Res. 2007;67(18):88398846. doi:10.1158/0008-5472.CAN-07-1649

22. Yuan Y, Wang WN, Wang BL, Zhu HY, Zhang BH, Feng MQ. Delivery of hydrophilic drug doxorubicin hydrochloride-targeted liver using apoAI as carrier. J Drug Target. 2013;21(4):367-374. doi:10.3109/1061186X.2012.757769

23. Kizek R, Adam V, Hrabeta J, et al. Anthracyclines and ellipticines as DNA-damaging anticancer drugs: recent advances. Pharmacol Ther. 2012;133(1):26-39. doi:10.1016/j.pharmthera.2011.07.006

24. Sugimoto T, Matijevic E. Formation of uniform spherical magnetite particles by crystallization from ferrous hydroxide gels. J Colloid Interface Sci. 1980;74(1):227-243. doi:10.1016/0021-9797(80)90187-3

25. Kumar SA, Peter YA, Nadeau JL. Facile biosynthesis, separation and conjugation of gold nanoparticles to doxorubicin. Nanotechnology. 2008;19:49. doi:10.1088/0957-4484/19/49/495101

26. Chou TC. Theoretical basis, experimental design, and computerized simulation of synergism and antagonism in drug combination studies. Pharmacol Rev. 2006;58(3):621-681. doi:10.1124/pr.58.3.10

27. Sodipo BK, Aziz AA. Non-seeded synthesis and characterization of superparamagnetic iron oxide nanoparticles incorporated into silica nanoparticles via ultrasound. Ultrason Sonochem. 2015;23:354-359. doi:10.1016/j.ultsonch.2014.09.011

28. Wang Y, Tu S, Pinchuk AN, Xiong MP. Active drug encapsulation and release kinetics from hydrogel-in-liposome nanoparticles. J Colloid Interface Sci. 2013;406:247-255. doi:10.1016/j.jcis.2013.05.081

29. Martinez-Torres AC, Zarate-Trivino DG, Lorenzo-Anota HY, AvilaAvila A, Rodriguez-Abrego C, Rodriguez-Padilla C. Chitosan gold nanoparticles induce cell death in HeLa and MCF-7 cells through reactive oxygen species production. Int J Nanomed. 2018;13:32353250. doi:10.2147/IJN.S165289

30. Mai Y, Yu JJ, Bartholdy B, et al. An oxidative stress-based mechanism of doxorubicin cytotoxicity suggests new therapeutic strategies in ABC-DLBCL. Blood. 2016;128(24):2797-2807. doi:10.1182/blood2016-03-705814

31. Savorani C, Manfe V, Biskup E, Gniadecki R. Ellipticine induces apoptosis in T-cell lymphoma via oxidative DNA damage. Leuk Lymphoma. 2015;56(3):739-747. doi:10.3109/10428194.2014.929673

32. Gonzalez-Moragas L, Yu SM, Benseny-Cases N, Sturzenbaum S, Roig A, Laromaine A. Toxicogenomics of iron oxide nanoparticles in the nematode C-elegans. Nanotoxicology. 2017;11(5):647-657. doi:10.1080/17435390.2017.1342011

33. Dobrovoiskaia MA, Clogston JD, Neun BW, Hall JB, Patri AK, McNeil SE. Method for analysis of nanoparticle hemolytic properties in vitro. Nano Lett. 2008;8(8):2180-2187. doi:10.1021/n10805615

34. Ricklin D, Hajishengallis G, Yang K, Lambris JD. Complement: a key system for immune surveillance and homeostasis. Nat Immunol. 2010;11(9):785-797. doi:10.1038/ni.1923

35. Chen FF, Wang GK, Griffin JI, et al. Complement proteins bind to nanoparticle protein corona and undergo dynamic exchange in vivo. Nat Nanotechnol. 2017;12(4):387-393. doi:10.1038/nnano.2016.269

36. Nguyen VH, Lee BJ. Protein corona: a new approach for nanomedicine design. Int J Nanomed. 2017;12:3137-3151. doi:10.2147/IJN. S129300

37. Poller JM, Zaloga J, Schreiber E, et al. Selection of potential iron oxide nanoparticles for breast cancer treatment based on in vitro cytotoxicity and cellular uptake. Int J Nanomed. 2017;12:32073220. doi:10.2147/IJN.S132369
38. Buchtelova H, Strmiska V, Dostalova S, et al. pH-responsive hybrid organic-inorganic ruthenium nanoparticles for controlled release of doxorubicin. Part Syst Charact. 2017;34(11):9. doi:10.1002/ ppsc. 201700289

39. Lo YI. Relationships between the hydrophilic-lipophilic balance values of pharmaceutical excipients and their multidrug resistance modulating effect in Caco-2 cells and rat intestines. $J$ Control Release. 2003;90(1):37-48.

40. Shekhar A, Nomura KI, Kalia RK, Nakano A, Vashishta P. Nanobubble collapse on a silica surface in water: billion-atom reactive molecular dynamics simulations. Phys Rev Lett. 2013;111(18):5. doi:10.1103/PhysRevLett.111.184503

41. Kamiya H, Iijima M. Surface modification and characterization for dispersion stability of inorganic nanometer-scaled particles in liquid media. Sci Technol Adv Mater. 2010;11(4):7. doi:10.1088/1468-6996/ $11 / 4 / 044304$

42. Bui TQ, Ngo HTM, Tran HT. Surface-protective assistance of ultrasound in synthesis of superparamagnetic magnetite nanoparticles and in preparation of mono-core magnetite-silica nanocomposites. $J$ Sci. 2018;3(3):323-330.

43. Ramalingam V, Varunkumar K, Ravikumar V, Rajaram R. Target delivery of doxorubicin tethered with PVP stabilized gold nanoparticles for effective treatment of lung cancer. Sci Rep. 2018;8:12. doi:10.1038/s41598-018-22172-5

44. Lee H, Lee K, Kim IK, Park TG. Synthesis, characterization, and in vivo diagnostic applications of hyaluronic acid immobilized gold nanoprobes. Biomaterials. 2008;29(35):4709-4718. doi:10.1016/j. biomaterials.2008.08.038

45. Rahman A, Cradock JC, Davignon JP. Dissolution and absorption of the antineoplastic agent ellipticine. J Pharm Sci. 1978;67(5):611614. doi:10.1002/jps.2600670509

46. Chen BL, Dai WB, He B, et al. Current multistage drug delivery systems based on the tumor microenvironment. Theranostics. 2017;7 (3):538-558. doi:10.7150/thno. 16684

47. Recouvreux MV, Commisso C. Macropinocytosis: a metabolic adaptation to nutrient stress in cancer. Front Endocrinol. 2017;8:7. doi: $10.3389 /$ fendo. 2017.00261

48. Schmid SL. Reciprocal regulation of signaling and endocytosis: implications for the evolving cancer cell. J Cell Biol. 2017;216 (9):2623-2632. doi:10.1083/jcb.201705017

49. Yameen B, Choi WI, Vilos C, Swami A, Shi JJ, Farokhzad OC. Insight into nanoparticle cellular uptake and intracellular targeting. J Control Release. 2014;190:485-499. doi:10.1016/j.jconrel.2014.06.038

50. Peetla C, Vijayaraghavalu S, Labhasetwar V. Biophysics of cell membrane lipids in cancer drug resistance: implications for drug transport and drug delivery with nanoparticles. Adv Drug Deliv Rev. 2013;65(13-14):1686-1698. doi:10.1016/j.addr.2013.09.004

51. Sok M, Sentjurc M, Schara M, Stare J, Rott T. Cell membrane fluidity and prognosis of lung cancer. Ann Thorac Surg. 2002;73(5):15671571. doi:10.1016/s0003-4975(02)03458-6

52. Geng QQ, Dong DF, Chen NZ, et al. Induction of p53 expression and apoptosis by a recombinant dual-target MDM2/MDMX inhibitory protein in wild-type p53 breast cancer cells. Int $J$ Oncol. 2013;43 (6):1935-1942. doi:10.3892/ijo.2013.2138

53. Zhang XY, Zeng GJ, Tian JW, et al. PEGylation of carbon nanotubes via mussel inspired chemistry: preparation, characterization and biocompatibility evaluation. Appl Surf Sci. 2015;351:425-432. doi:10.1016/j.apsusc.2015.05.160 


\section{Publish your work in this journal}

The International Journal of Nanomedicine is an international, peerreviewed journal focusing on the application of nanotechnology in diagnostics, therapeutics, and drug delivery systems throughout the biomedical field. This journal is indexed on PubMed Central, MedLine, CAS, SciSearch ${ }^{\circledR}$, Current Contents ${ }^{\circledR} /$ Clinical Medicine,
Journal Citation Reports/Science Edition, EMBase, Scopus and the Elsevier Bibliographic databases. The manuscript management system is completely online and includes a very quick and fair peer-review system, which is all easy to use. Visit http://www.dovepress.com/ testimonials.php to read real quotes from published authors. 